\title{
Necrològica
}

\section{En la mort de Ramon Xirau}

El 26 de juliol de 2017 va morir Ramon Xirau. Havia nascut a Barcelona l'any 1924, fill del filòsof Joaquim Xirau, degà de l'anomenada Universitat Autònoma de Barcelona republicana. Amb la família s'exilià a França, i al cap de poc temps, a Mèxic, on estudià, va ser professor i escriptor prolífic. Es nacionalitzà mexicà l'any 1955. A finals de la dècada de 1970 començà a viatjar a Espanya, on va rebre diferents reconeixements. Va ser investit doctor honoris causa per la Universitat Autònoma de Barcelona l'any 1984, conjuntament amb Eduard Nicol, en un acte presentat per Jordi Maragall.

\section{«et miren / Ocell del Pensament»}

Poeta, filòsof, assagista, crític literari. L'ordre d'aquests termes més aviat depèn dels possibles interessos del lector, i pot quedar el dubte de si no resulta més exacte fondre el segon i el tercer, ja que més aviat practicà una filosofia assagística. La majoria dels seus escrits són breus, concisos. S’hi palesa sempre la voluntat que siguin clars, d'aclarir-se durant l'acte mateix de ser escrits.

Quan es parla de Ramon Xirau el tòpic diu que s'ha de consignar i repetir sense descans que fou un «home pont». Així se li acudí a Octavio Paz i no hi fa res insistir-hi. El també poeta i assagista mexicà — que era deu anys més gran i que va morir ara en fa vint - va saber retratar molts cops el seu col.lega, i aquesta imatge és prou eficaç: un home que unia els diversos sabers, gèneres literaris i llengües que conreava, també entre cultures de les dues bandes de l'Atlàntic (i no només les més òbvies). S'havia exiliat amb els seus pares perduda la guerra del 36. Després d'una breu estada a França recalà amb la família a Mèxic, on seguí estudiant i féu la carrera de filosofia.

Escriptor discret, meditatiu i elegant, el reconeixement més gran per part d'un públic considerablement ampli li arribà d'una manera més aviat inesperada, a través d'un autèntic best-seller en el ram en què treballava: la seva Introducción a la historia de la filosofía, el manual que introduí en la matèria una colla llarga de generacions d'estudiants mexicans de diferents disciplines des de 1964 i que va ser producte de moltes reedicions i d'algunes actualitzacions al llarg dels anys. Curiosament, aquest llibre no es pot considerar un simple manual, perquè tot ell té una tonada personal, una singularitat, un saber 
dir que és del tot infreqüent en el gènere, per bé que constitueix un estil constant en l'autor. Una mica més tard publicà una altra obra que hi té un parentiu directe i pel qual Xirau ha pogut ser més conegut aquí - a part de l'obra poètica-: El desarrollo y las crisis de la filosofía occidental. En tot cas, el fet que fos publicada dins la col-lecció "Libros de Bolsillo» - llavors molt divulgada i assequible- , de la madrilenya Alianza Editorial (1975), va contribuir a difondre-la. Són dos llibres que, d'altra banda, queden com a testimonis escrits d'una llarga labor com a docent en diferents institucions mexicanes.

Però cal dir que, tret d'aquestes dues obres, que són peculiars en la trajectòria de Xirau, ell no era exactament un historiador ni un divulgador. A més, es mostrà completament reticent a tractar el tema de la filosofia de la història, per no parlar de l'historicisme. El sol títol de l'assaig del 1959 ja ho anuncia, amb una proposta que apunta vers una altra direcció: El péndulo y la espiral. Com a filòsof, ja ha quedat assenyalat que era bàsicament un assagista. No va escriure cap gran llibre en aquest terreny perquè pensava assajant, allunyat de la sistematització i del tractat, en escrits majoritàriament sintètics, suggestius, que podien prendre com a punts de referència Pascal o Wittgenstein, Erasme o Mounier, Descartes o San Juan de la Cruz, però per buscar la paraula mig dita, mig callada, en un camí indecís i expectant entre la filosofia i la poesia. Expressat en vers: «Difícil / dir-te / (records del vent i llis) / Difícil dir-te / món breu llis» (Natures vives).

En la crítica literària, que conreà amb assiduïtat, parava molta atenció a les paraules dels textos analitzats, però hi buscava indicis i derivacions propers als seus interessos més personals: l'apuntat dubte entre el que s'ha dit i no s'ha dit, un sentit interrogant de la mística (sense cap misticisme, ni en la poesia), la presència del que s'ha perdut o que encara és absent i que ja s'endevina aquí, a través de la contemplació, de la rememoració o del mer text escrit. S'endevina un suau bergsonisme cristianitzat, tant d'una època.

En aquest terreny de la crítica aportà una manera d'atansar-se a una sèrie llarga sobretot de poetes molt coneguts i estudiats, sobre els quals aportà un sentit molt peculiar i alhora entenedor. Féu una crítica de lector, de bon lector, que escrivia sobretot sobre els poetes que li importaven: Jorge Guillén, Juan Ramón Jiménez, César Vallejo i els mexicans José Gorostiza, Xavier Villaurrutia o el mateix Octavio Paz, entre molts d'altres. No només interpretà aquests poetes, sinó que també hi mantingué un diàleg íntim. Això també es nota en la seva pròpia poesia, tota escrita en llengua catalana, que de vegades es proclama maragalliana, però potser més per la vocació de la vivacitat de la paraula que no pas per res més. La vinculació mexicana — mitjançant la relació lectora amb els poetes que he esmentat - li donà una tonalitat molt especial, ja que no esborrà gens l'empenta poètica catalana. I aquí cal afegir-hi que molts d'aquests llibres van ser publicats a Mèxic — també molt aviat a Barcelona—, en edicions bilingües, de manera que segurament ha estat el poeta català més editat, conegut i reconegut en aquells indrets (i potser no només del seu temps, al costat, com a molt, d'Agustí Bartra). És una poesia de les coses petites, de la llum — la lucidesa-, de la vida quotidiana, feta de descripcions paisatgís- 
tiques que també són quadres i tonades musicals (molt sovint dedica poemes que deixen veure predileccions per pintors i per músics, i sense el més mínim bri culterà).

D'insistir en la imatge de l'home pont, i de la unió entre l'origen català - $\mathrm{i}$ de filòsof- i el destí mexicà — i de poeta—, resulta convenient indicar que Ramon va viure dues tragèdies íntimes determinades per dos homes que no per casualitat duien el mateix nom: Joaquim Xirau i Palau (Figueres, 1895), el seu pare, filòsof i pedagog, que morí jove en un accident (Mèxic, 1946), i Joaquín Xirau Icaza (Mèxic, 1950), el seu fill, economista i poeta, que encara va morir més jove (Boston, 1976). La memòria de tots dos es troba, de manera discreta - tot és discreció en Ramon- però molt intensa, en racons de tota la seva obra, començant per la poètica, on hi ha moltes referències directes i unes altres de més el.líptiques. El fill Joaquim tot just havia arribat a publicar algun estudi i pòstumament, el 1977, s'edità el seu únic llibre com a poeta. El poema de Ramon, "Cant de Joaquim», dins Dit i escrit, inclou intercalada la traducció catalana quasi completa del poema «Eclipse», de Joaquim fill. I a ell va dedicat el poema de Natures vives que ja ho diu tot en el títol: «Job?». La continuïtat amb Joaquim pare, a més de tantes presències en la poesia, també és perceptible, inevitablement, en tota la seva obra més especulativa, com una herència rebuda i recreada, és a dir, d'una lliure modulació d'idees i creences. És el cas sobretot de la suau religiositat, un cristianisme encara més lleu, encara menys doctrinal, un tret que ja havia notat Antonio Machado en el pare.

El crític literari, el filòsof assagista i el poeta comparteixen l'estil sobri i net. És una escriptura que sempre sona a veu parlada, que transmet al lector una respiració sincopada, un flux verbal lent que conté petits i sovintejats rampells expressius. Frases o versos curts, que tendeixen a ser secs i tallants, amb una tendència a combinar l'exposició calmada que tot d'una es precipita, a base de petits sobresalts, que expliciten molt bé la seva concepció del dir, l'escriure i el descriure. «Per la finestra / veig els jardins / ara que escric els veig» («Record de Vallejo»).

La tensió - la relació i els límits- entre poesia i coneixement és una preocupació constant de Xirau, que es copsa molt bé en el seu mateix estil, poètic $i$ en prosa. Això li permet moure's subtilment sobre un fons fonamentalment alterat, sobre un neguit que sempre batega en els seus escrits, però que pot passar desapercebut en una primera lectura. Al cap i a la fi, la seva condició de fugit i refugiat d'una guerra, des de l'adolescència, acabà per prendre en ell la forma d'un apocalipsi ja esdevingut, sense grans escarafalls, però fet d'asprors i espants soterrats. De fet, va escriure un apocalipsi explícit, molt seu - tant, que només té en compte una petita part de l'Apocalipsi canònic_- un dels seus pocs poemes llargs: L'anyell (una peça de maduresa, 1981). La fi del món és aquí present, com en molts assaigs, i no només ni primordialment en el sentit catastròfic literal, sinó sobretot com la manera d'assenyalar la condició d'haver-se quedat sense món, en la pura indistinció de tot, adreçant-se a l'anyell del títol: «Ja res no és fals / ens diu el teu secret: / ja res no és fals». O en les paraules d'un altre apocalipsi revelació anterior: «Estem a punt de fondre / i 
el món és molt més foc que el foc d'Heràclit, / estem a punt de caure / i el món ja és tan caiguda / com la caiguda del primer» («Plomada», a Les platges). D’altra banda, els ecos explícits de la guerra del 36 són més perceptibles a mesura que se n'allunya temporalment (és el cas del seu darrer llibre poètic, publicat l'any 1999 i titulat Indrets del temps).

Es pot considerar que amb ell desapareix l'últim vestigi d'una determinada cultura que no sembla que tingui cap continuïtat en les lletres catalanes -entengui's aquí, sobretot, un tarannà, una modulació, una mena de mirada. I no serà per ell, que mantingué constantment viva una manera de fer $\mathrm{i}$ d'entendre, i sense deixar d'inserir-se a la cultura mexicana de recepció. El cas és que, a través del seu pare, se sentí continuador d'un cert filosofar i, més en general, d'una actitud intel.lectual que atenia més un reconeixement de procedència que no pas una tradició o escola. Era un saber formar-ne part, sense grans afirmacions ni constrenyiments. A través del seu pare havia conegut de molt jove, a Barcelona, Jaume Serra Hunter, Eduard Nicol, Josep Ferrater Mora, Josep Calsamiglia i Jordi Margall. Als dos primers - més a Nicol, ja que el primer morí molt aviat - els va seguir tractant en el comú exili mexicà, i amb els altres no perdé mai el contacte amical. Va escriure sobre tots, en textos que combinaven l'explicació de les respectives personalitats, amb unes interpretacions del que havien anat aportant (per exemple: va redactar el capítol «La filosofía catalana», inclòs a l'edició espanyola de la Historia del pensamiento filosófico y científico, de Ludovico Geymonat, en concret, el tercer volum, dedicat al segle xx, 1985). També era el més jove de tots, de manera que la seva mort accentua la sensació d'un punt i final, especialment si es té en compte que a Barcelona només s'han anat publicant els seus llibres de poesia (i la Poesia completa l'any 1996, avui ja no completa del tot), però ni un sol llibre d'assaig ni de crítica literària, tot just alguns i dispersos articles.

Queda el llegat mexicà, que és molt considerable i tangible. Diálogos és el nom que dugué la revista literària que cofundà i codirigí (1964-1985), on publicà textos dels més variats escriptors del moment, començant per Octavio Paz i seguint amb Roger Callois, Maurice Blanchot, María Zambrano, Carlos Fuentes, Susan Sontag, Severo Sarduy, José Lezama Lima, Eugene Ionesco, Milan Kundera i un molt llarg etcètera. I el diàleg — real i sostingut- va ser una forma que practicà $a m b$ ganes. Va mantenir amistat amb Eric Fromm, amb qui va escriure un llibre: The Nature of Man (1968). Un poema dedicat a un altre amic de tota la vida, l'altre noi exiliat amb els seus pares, Manuel Duran (un any més jove, també barceloní, també crític de la literatura, també poeta, autor del llibre Reason in exili: Essays on Catalan philosophers, 1994), a qui li propicià tota una declaració vàlida per a tots dos: «No vull cridar ni tu -m'ho dius - no vols tampoc / cridar» (Les platges). El context es referia sobretot a la poesia social d'un moment donat, però les paraules valen per tot el que va ser —escriure i fer- Ramon Xirau. 


\section{Obra destacada}

La poesia es compon de nou llibres: Deu poemes (1951), L'espill soterrat (1955), Les platges (1974), Graons (1979), Dit i descrit (1983), Ocells (1986), Natures vives (1991), Nous poemes (1992-1994) i Indrets del temps (1999). Cal afegir-hi encara un recull de poemes escrits i publicats entre 1945 i 2004, inclosos com a «Poemes dispersos» dins del volum de Poesia completa (2007).

Els llibres d'assaigs - i no diguem els assaigs breus, publicats en revistes i en llibres d'altres autors - són innombrables, i n'hi ha molts de recollits en diferents antologies. Per destacar-ne alguns, a més dels esmentats més amunt, citarem: Sentido de presencia (1953), Palabra y silencio (1968), De ideas y no ideas (1974) i El tiempo vivido (1985).

D'entre l'abundant crítica literària: Mito y poesía (1964), Genio y figura de Sor Juana Inés de la Cruz (1967), Octavio Paz, el sentido de la palabra (1970), Dos poetas y lo sagrado: César Vallejo y Juan Ramón Jiménez (1980).

Va ser editor de diferents llibres de Joaquim Xirau, incloses les Obras completas (4 volums, 1998-2000). També, entre d'altres, de recopilacions de textos, com ara les antologies Idea y querella de la Nueva España (1974) o Otras Españas: Antología sobre literatura del exilio (2012).

\section{Bibliografia essencial}

La poesia va ser recollida en el volum Poesia completa (Barcelona, Columna, 1996), i una mica més completada, allò que en diuen "definitiva», amb el mateix títol, en format bilingüe, traducció d'Andrés Sánchez Robayna, Mèxic, FCE, 2007. Una àmplia selecció de la crítica literària es troba a Entre la poesía y el conocimiento: Antología de ensayos críticos sobre poetas y poesía iberoamericanos, Mèxic, FCE, 2001. 